\title{
A Dialogical Model for Users' Participation
}

\author{
HOANG-ELL JENG \\ Delft University of Technology \\ The Netherlands
}

\begin{abstract}
This paper is about a method for the structuring of design dialogue for participatory design in a face-to-face design discussion. Participatory design is an important design approach in architecture and urban design, which has become part of professional practice. I examine the problem of participatory design from the perspective of cognitive science and design methodology to see how the interaction between the design activities in the material world and the thinking of design concepts is carried out through dialogue interaction. The result of this study is a new method of participatory design, a framework for participation-based design guidelines (PBDGs). The method makes a practical contribution to architecture and urban design processes in which participation occurs in the early stages. It focus on the generation of design guidelines. It investigates the process of group planning and develops a computational model for further the realization of computer-based information systems to support that process.
\end{abstract}

\section{INTRODUCTION}

Since the mid-1960s, there has been an important movement towards increasing the participation of citizens in determining their built environment. At first, the movement was associated with social-political ideologies and rhetoric. By the end of the 1970s, participatory design had become an accepted component of professional practice. The objectives of the movement became more pragmatic and more modestly focusing on exchanging practical information, resolving conflicts, and supplementing design (Sanoff 1988). Today, participatory design is in a new phase. Traditional participatory design methods are seen as insufficient to fulfil an increasing demand for dialogue.

Based on empirical knowledge of participatory design and through the review of participatory design methods (Jeng 1995), I generate the assumption that a computerbased system that helps in the structuring of design dialogue may be a useful tool in supporting designers in the participatory design process.

In participatory design, design concepts are generated through discussion, dialogical interactions, in which the interchange of normative and supporting factual descriptions builds a collective design discourse. A systematic analysis of such design dialogue helps in capturing the reasoning process of the design discussion, and in understanding conflicts.

In current practice, because of the lack of method applied in understanding design dialogue, participatory designers are normally anxious to guide the group to produce design schemes. To the designer at least, the drawings of design schemes appear to be better formulated. In this sense, only a small part of the discussion is considered to be useful in terms of direct contribution to the design. Further, important information may be neglected in the process and the result may be unsatisfactory.

The result of a participatory design may include verbal and graphic statements of a design project. In participatory design, most design concepts are in the form of verbal statement. Natural language is used as the main medium of design discussion. Graphic statements mostly do not carry reasons or grounds that can be useful for further adjustment if changes of "components of situation" (Brown \& Fraser 1979) should occur.

Participatory design is part of the overall design process. The formulation of participatory design dialogue is a subtask that contributes to a broad design task. Participatory design may involve complex social-political factors. I scale down to focus on the design reasoning of a small group engaged in design discussion, and emphasised on the early stages of participatory design, problem defining and problem-locating, where generating collective normative statements and providing factual descriptions are more important than making final, specific design decisions.

\section{ADEQUACY CRITERIA FOR A PARTICIPATORY DESIGN TOOL}

The development of a tool for supporting participatory design requires a deep examination of the adequacy criteria for participatory design tools. The five criteria developed from a case study (Jeng 1995) are: 
1) validity - that the tool should be able to achieve its functions. The tool should support the structuring of the design dialogue. Through which, participants in a design discussion can easily understand the agreements and/or the disagreements.

2) effectiveness - that the tool should be able to support its users in achieving their goals. The tool is designed for the participatory designers whose main goal is to facilitate the design discussion, and to lead the design discussion to a satisfactory result.

3) efficiency - that the resources needed to achieve the goal by using the tool should be minimal. The application of the tool should use fewer resources than is currently the case. If the use of the tool saves time, manpower and the operation of the tool is not such time consuming in comparison to existing methods, then the efficiency is high.

4) reliability - that the tool should be generally applicable. Users of the tool should be able to operate the tool in a wide variety conditions. Since participatory design normally takes place in a natural setting, if the tool can not be operated on site, the reliability is limited.

5) robustness - that the tool should lead to new development. The method which has led to the development of the tool, should be able to employ further developments and extensions to develop improved tools.

\section{DEVELOPMENT OF A PARTICIPATORY DESIGN METHOD}

The most earliest development of computer-based information systems in supporting participatory design is the issue-based information system (IBIS). (Dehlinger \& Protzen 1972). The structure of IBIS is utilized as a unifying format to collect, store and retrieve information that will be applicable to a meaningful debate. IBIS was originally developed to serve as an argumentation procedure for decision-making groups to use in the coordination and support of debate over political decisions. "The IBIS can be used as a procedure for arguing design, planning, and policy making decisions on any topic." (Grant 1982: 203).

Negative criticism of IBIS arises from two types of problems: the low efficiency of computer-aided tools and the ambitious attempts of which lead to over-load of information. First, the computer-aided systems of IBIS were still experimental in the early 1970 s. Tools applied in IBIS, such as the tree-structure of issue maps, tables of matrices and issue forms were constrained by the then current stage of development of computer technology: many technical problems can now be more easily solved because of the presentday developments of hypertext-based systems. Second, IBIS fails to further decompose design arguments and associate issues in such a way that users can easily manipulate, and transform them into forms. To date we have better computer technology in solving the first problem. As to the second problem, we have to reexamine the method applied in structuring design concepts.
One main category of design concepts is norm. A norm can be states or actions to bring about states, and it is expressed by a normative statement. Such a norm can be a goal, a need or an objective. Normally the result of a design discussion serves as a set of normative descriptions, and based on which future designers or implementors may carry out their actions. Normative descriptions are generated through design reasoning processes and can be seen as in the form of a hierarchical structure. (See Fig. 1). This assumption is the point of departure for the development of the method, and on the basis of that assumption I apply Tzonis' model of the "Conceptual System" (Tzonis et al. 1978), which is a "minimum necessary structure" of architectural thinking in understanding the internal reasoning process in group design.

The structure of the Conceptual System is a primitive universal organization which is common to any design discourse. It contains two branches: the deontic and the factual. Deontic descriptions will lead to the generation of the design directive and the justification of the design norm. A directive also has the characteristics of a norm. If one norm can bring about another norm, then the first norm is also called directive. Factual implication or implied statements are about "facts". In the Conceptual System, fact refers to factual statements that have the implied nature that serve as mediation between norm and directive. The three objects, norm $(\mathrm{N})$, directive (D) and fact $(\mathrm{F})$, consist the Kernel of Conceptual System (KCS). Factual descriptions include two modules, backing and base. Backing is a descriptive statement that says why the fact component is true. Base provides arguments for the truth value of the backing. (See Fig. 2). An architectural discourse may consist several design arguments, where one argument may be followed by other arguments in a linear sequence. (See Fig. 3).

To develop a cognitive structure of a group design discussion, I further develop a three-layered model (see Fig.

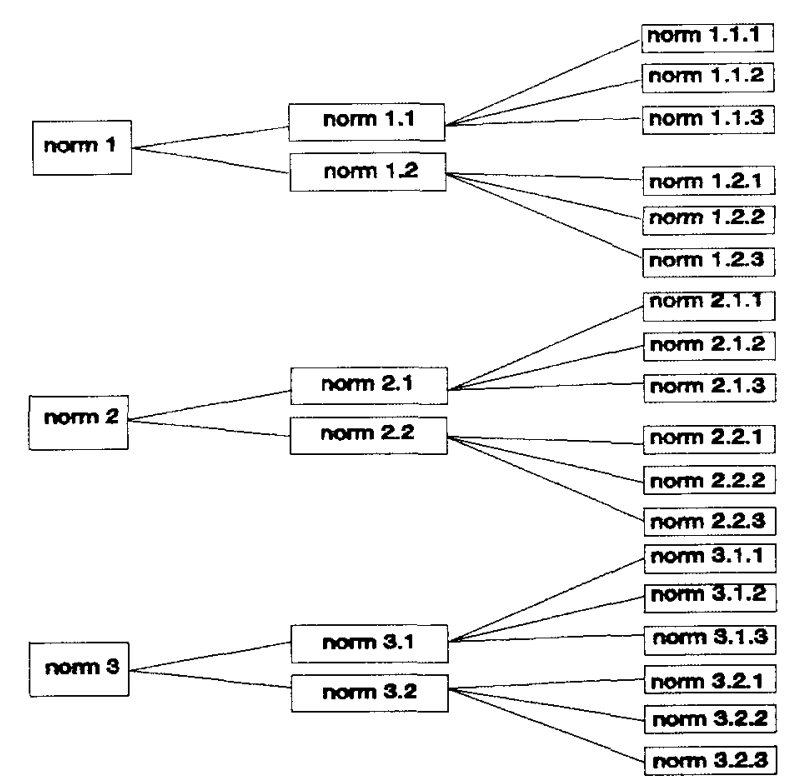

Fig. 1. Hierarchical structure of design norms. 

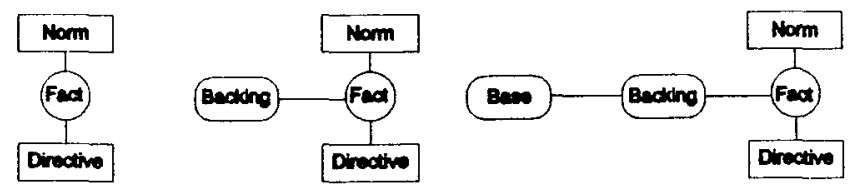

Fig. 2. Kernel of Conceptual Systems (KCS). (left); KCS with the backing module. (middle); KCS with the base module. (right). After Tzonis et al. 1978.

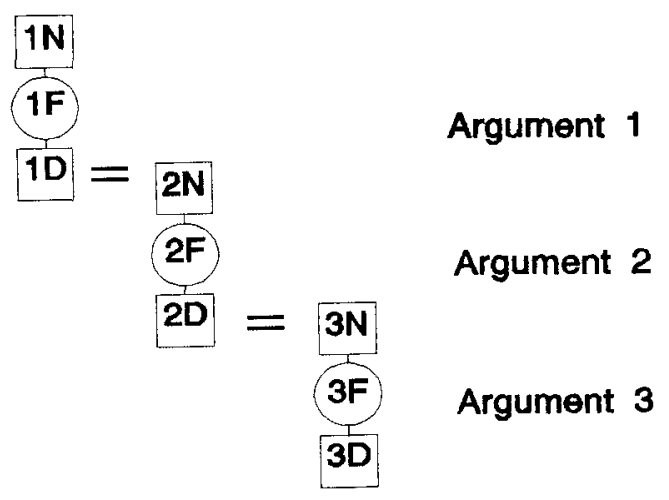

Fig. 3. A linear sequence of design arguments.

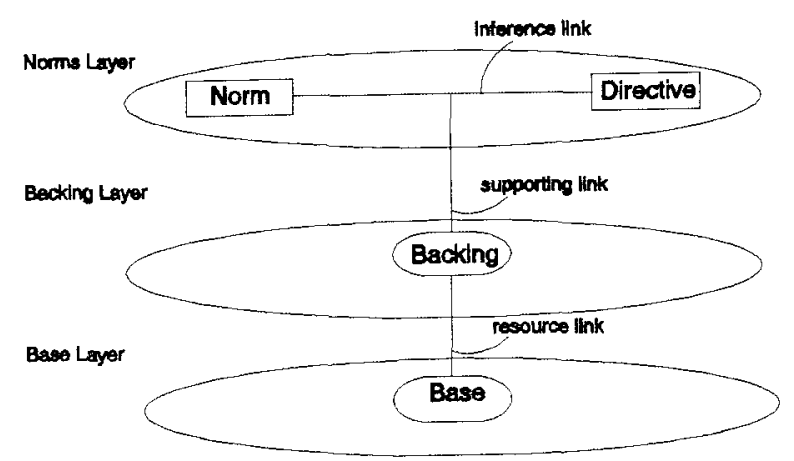

Fig. 4. Three-layered conceptual systems.

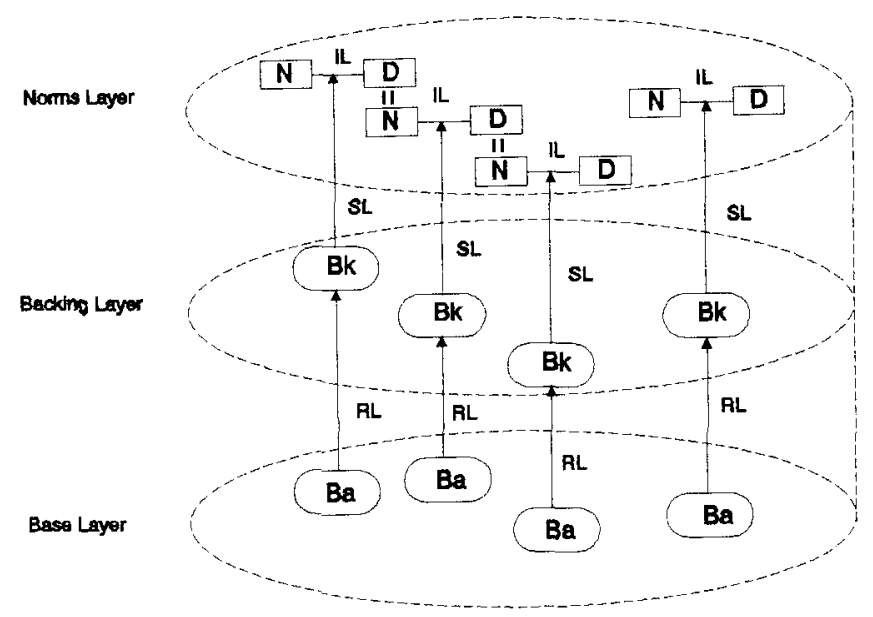

Fig. 5. A joint conceptual systems.
4), and on the basis of the model, I developed a Joint Conceptual System (JCS) (see Fig. 5). JCS represents the shared design concepts generated in a design discussion. The norms layer is for normative descriptions. The backing layer is for reasons for being for or against the inferences between two norms. The base layer is for references for the reasons.

\section{FRAMEWORK FOR PARTICIPATION-BASED DESIGN GUIDELINES}

The joint conceptual system model is the basis for the development of the framework for participation-based design guidelines (PBDGs). (See Fig. 6). Constructs of PBDGs are under three categories: 1) structures, 2) objects and 3) relations. Structures are the basic frameworks of PBDG. Objects are design concepts excerpted from a design discussion. Tzonis (1992) has developed a representation of architectural knowledge, in which he specifies the concepts of performance, operation and morphology as the kernel of design thinking. Performance refers to the conditions which a perspective build environment is intended to bring about, or the degree to which a scheme of building brings these conditions about. Operation refers to the process that make up the use of a building, and the role of form in these processes. Morphology is used to refer to the formal aspects of a building or an urban area. Further, there are certain properties of norm. Von Wright (1963) has defined the distinction between the expression of obligation and permission as used in normative descriptions. To Von Wright's list of properties of norm, I add two more: suggestion and endcommand. Other two categories of objects are of factual descriptions and questions. Relations are the link between two objects. Base on the Conceptual system, three kinds of relation are defined: inference link, support link, and reference link. In analyzing a joint conceptual system, since there are more than one individual's belief systems, three other types of relation are necessary - against link, contradiction link, and modification link.

The framework of PBDGs helps in structuring design concepts of participatory design. Since the structuring of a set of PBDGs is carried out simultaneously, the consistency of the representation can be maintain, and misinterpretation can be reduced to a minimum scale.

\section{APPLICATIONS OF THE PBDG TOOL}

In a design discussion, normally the participants want to see their opinions being taken into consideration. From PBDGs, we can understand what concerns a particular group of users have about a particular built environment. It is not to see what kind, or type, of design they prefer, but to understand how they think about the design, what their joint intentions are, what factual descriptions they use to support their arguments, and the extent to which the factual descriptions are changed in time. By documenting issues, points of view, alternatives and debates in the guide frames, the designer and the participants will be able to generate more workable 


\begin{tabular}{|c|c|}
\hline \multirow[t]{2}{*}{ Structures } & $\begin{array}{l}\text { A. Level: } \\
\text { Level refers to the linear, hierarchical relation between norms. When one norm } \\
\text { is higher than another norm then there are two Levels. }\end{array}$ \\
\hline & $\begin{array}{l}\text { B. Layer: } \\
\text { Layer refers to the distinction between types of information: the Layer of } \\
\text { norms, the Layer of backing, and the Layer of base. }\end{array}$ \\
\hline \multirow[t]{4}{*}{ Objects } & $\begin{array}{l}\text { A. Objects of normative descriptions } \\
\text { 1. performance norm (PN): PN refers to norms that have the characteristics of } \\
\text { Performance } \\
\text { 2. operation norm (ON): ON refers to norms that have the characteristics of } \\
\text { Operation } \\
\text { 3. morphology norm (MN): MN refers to norms that have the characteristics } \\
\text { of Morphology. }\end{array}$ \\
\hline & $\begin{array}{l}\text { B. Operators of norms } \\
\text { 1. obligatory (norm) (O-): When a norm has the operator of ought to or must } \\
\text { not, then it is a norm with an "O-". } \\
\text { 2. permissive (norm) (P-): When a norm has the operator of may, then it is a } \\
\text { norm with a "P-". } \\
\text { 3. suggestion (norm) (S-): When a norm has the operator of suggestion, then } \\
\text { it is a norm with a "S-". } \\
\text { 4. end-command (E-): When there is no further generation of a norm, then an } \\
\text { "E-" is added to the norm. }\end{array}$ \\
\hline & $\begin{array}{l}\text { C. Factual descriptions } \\
\text { 1. classificatory fact }(C L-F): C L-F \text { is a statement that says the state of a lower } \\
\text { norm is one of the cluster of the state of the higher norm. } \\
\text { 2. conditional or causal fact }(C-F): C-F \text { is a statement that describes the state } \\
\text { in which the tower norm is the condition for bringing about the state } \\
\text { requested by the higher norm. } \\
\text { 3. resource to authority }(R-A): R-A \text { is a resource to authority. } \\
\text { 4. resource to a general law }(R-G): R-G \text { is a resource to a general law. } \\
\text { 5. resource to experience }(R-E): R-E \text { is a resource to empirical experience. }\end{array}$ \\
\hline & $\begin{array}{l}\text { D. Questions } \\
\text { 1. classifications of objects }(\mathrm{Q}-\mathrm{C}) \text { : "What is } \mathrm{X} \text { ?" }(\mathrm{X} \text { is a norm/fact). } \\
\text { 2. justification or generation of norms }(\mathrm{Q}-\mathrm{N}) \text { : "What will } \mathrm{X} \text { bring about?" or, } \\
\text { "How can } \mathrm{X} \text { be achieved?" }(\mathrm{X} \text { is a norm). } \\
\text { 3. backing for inferences }(\mathrm{Q}-\mathrm{B}) \text { : "Why will doing } \mathrm{Y} \text { bring about } \mathrm{X} \text { ?" ( } \mathrm{X} \text { and } \mathrm{Y} \\
\text { are norms). } \\
\text { 4. base for the backing }(\mathrm{Q}-\mathrm{R}) \text { : "How do you know that doing } \mathrm{Y} \text { will bring } \\
\text { about } \mathrm{X} \text { ?" (X and } \mathrm{Y} \text { are norms). } \\
\text { 5. background information }(\mathrm{Q}-\mathrm{B}) \text { : "Will the mayor joint our meeting today?" } \\
\text { 6. meta-assumptions }(\mathrm{Q}-\mathrm{M}) \text { : "Is participatory design necessary?" }\end{array}$ \\
\hline Relations & $\begin{array}{l}\text { A. Inference link (IL): is-a-higher/lower-norm-of } \\
\text { B. Against link ( } A L) \text { : is-a-reason-against } \\
\text { C. Support link ( } S L) \text { : is-a-reason-for } \\
\text { D. Resource link (RL): is-a-resource-to } \\
\text { E. Contradiction link }(C L) \text { : is-in-contradiction-with } \\
\text { F. Modification link (ML): is-a-modification-of }\end{array}$ \\
\hline
\end{tabular}

Fig. 6. PBDG constructs.

design guidelines, in addition to any given, top-down, architectural programme.

A set of PBDGs is a product of group intentions, and it is a design problem defined by the participatory design process. Winston (1992: 18) has said, "Once a problem is described using appropriate representation, the problem is almost solved." The framework of PBDGs, with the support of computer-based system, can be used as a tool to support designers. By using a hypertext-based PBDG tool, factual and normative descriptions, and the relations between them 
are explicitly marked with nodes and links. (See Fig. 7). Here are three phases of operating the PBDG tool: 1) representation, 2) editing information, and 3 ) reviewing.

step one: representing information. The first step is to transform design concepts into visible verbal statements. Words uttered by the participants of the design discussion must be transposed in texts for further manipulation. When graphics - drawings or photos - are used, descriptions of corresponding concepts must be attached.

step two: editing information. The second step is editing information. It requires the intensive activities of understanding and analyzing of concepts. Activities in this step include: developing the structure of the design guidelines, locating statements on the system, and associating statements.

step three: reviewing information. The third step is to review the PBDGs and use them as a basis to further design guidelines. When there is conflict, participants can by reviewing these structured design concepts understand the origin of the conflict.

By using the PBDG tool designers can check whether the design work at hand is following the given design guidelines or, if there is conflict, what judgements to make. Or, if there is a change of fact, what decision to make.

Participatory design may involve complex factors. For a successful application of a participatory design process, certain things are necessary, or at least need to be taken into consideration: a method that helps in formulating the process, trained facilitators working as a team, cooperation of the participants, careful control of the process, sufficient financial support, a social context that supports the participatory design approach, sufficient time and the appropriate timing of participation consultation.

By using the PBDG tool, the design project may maintain its holism, the creativity of designers may not be constrained, and the participation of users may also be accomplished. The PBDG tool can be applied to architectural and urban design

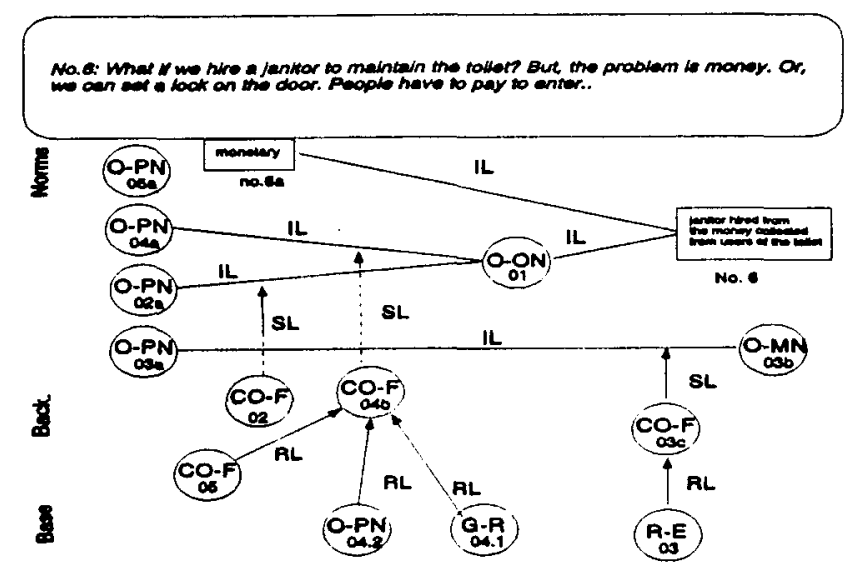

Fig. 7. An example of a set of PBDGs. practices wherever specified design guidelines are required before the process of physical design begins.

\section{CONCLUSION}

By using the PBDG tool, an explicit record of the process of the development of PBDGs is explicitly represented. Moreover, a well-organized set of PBDGs with the support of computer technology is a useful tool for both the users and the designers in a following stages of the participatory design process.

There is a thinking process underlies the generation or reasoning of design statements, principles, and design solutions. Collective design reasoning must be acceptable at least to the participants of a design discussion. It is at least conventionally true in the context when such a thinking process is applied, but it is not necessarily true in other contexts. A set of PBDGs is generated in a particular context for a particular design project. This is the constraints in applying a set of PBDGs.

The framework for PBDGs is developed based on the dialogical model of group design discussion. Such a dialogical model can be used as a reflective tool for improving the understanding of the design process by professionals and users. The PBDG tool can be extended to the development of computer-supported cooperative work among multi-disciplinary experts. It can also lead to the development of software to support concurrent problem-solving, in which through computer networks agents in different locations are in dialogue .

\section{REFERENCES}

Brown, P. \& C. Fraser. (1979). Speech as marker of situation. In K. R. Scherer \& H. Giles eds. Social Markers in Speech. Cambridge: Cambridge University Press. 33-108.

Dehlinger, H. \& J. P. Protzen. (1972). Some consideration for the design of Issue Based Information Systems. DMG-DRS Journal 6(2).

Grant, D. P. (1982). Issue-based information system (IBIS). In S. A. Olsen. ed. Group Planning and Problem-Solving Methods in Engineering Management. New York: John Wiley \& Sons.

Jeng, H.E. (1995). A Dialogical Model for Participatory Design: a computational approach to group planning. Doctoral Dissertation. Delft: Delft University of Technology.

Sanoff, H. (1988). Participatory design in focus. Arch. \& Comport. / Arch. Behav. 4(1). 27-42.

Tzonis, A. (1992). Huts, ships and bottlerracks: design by analogy for architects and/or machines. In N. Cross, K. Dorst \& N. Roozenburg. eds. Research in Design Thinking. Delft: Delft University of Technology. 139-164.

Tzonis, A., R. Berwick \& M. Freeman. (1978). Discourse Analysis and the Logic of Design. Harvard G.S.D. Publication. Series in Architecture A-7817.

Winston, P. H. (1992). Artificial Intelligence. 3rd ed. Reading, MA: Addison-Wesley.

Wright, G.H. von. (1963). Norm and Action: a logical enquiry. London: Routledge \& Kegan Paul. 